\title{
Augmented serum level of major histocompatibility complex class I-related chain A (MICA) protein and reduced NKG2D expression on NK and $T$ cells in patients with cervical cancer and precursor lesions
}

\author{
Naela A Arreygue-Garcia ${ }^{1}$, Adrian Daneri-Navarro ${ }^{1}$, Alicia del Toro-Arreola ${ }^{1}$, \\ Angel Cid-Arregui ${ }^{2}$, Oscar Gonzalez-Ramella1, Luis F Jave-Suarez ${ }^{3}$, \\ Adriana Aguilar-Lemarroy33, Rogelio Troyo-Sanroman¹, Alejandro Bravo- \\ Cuellar $^{3}$, Vidal Delgado-Rizo ${ }^{1}$, Trinidad Garcia-Iglesias ${ }^{1}$, \\ Georgina Hernandez-Flores ${ }^{3}$ and Susana del Toro-Arreola*1
}

Address: ${ }^{1}$ Laboratorio de Inmunología, Departamento de Fisiología, Centro Universitario de Ciencias de la Salud, Universidad de Guadalajara, Guadalajara, Jalisco, México, ${ }^{2}$ Tumor Gene Therapy German Cancer Research Center (DKFZ) Im Neuenheimer Feld 280 69120-Heidelberg, Germany and ${ }^{3}$ División de Inmunología, Centro de Investigación Biomédica de Occidente, Instituto Mexicano del Seguro Social, Guadalajara, Jalisco, México

Email: Naela A Arreygue-Garcia - qfb_naela@hotmail.com; Adrian Daneri-Navarro - daneri@cucs.udg.mx; Alicia del ToroArreola - alicia.del.toro@cucs.udg.mx; Angel Cid-Arregui - a.cid@dkfz-heidelberg.de; Oscar Gonzalez-Ramella - ogramella@prodigy.net.mx; Luis F Jave-Suarez - lfjave@yahoo.com; Adriana Aguilar-Lemarroy - adry_al@yahoo.de; Rogelio Troyo-Sanroman - rogeliotroyo@hotmail.com; Alejandro Bravo-Cuellar - abravoc@prodigy.net.mx; Vidal Delgado-Rizo - vidal@cencar.udg.mx; Trinidad Garcia-Iglesias - tgarcia@cucs.udg.mx; Georgina Hernandez-Flores - geodic1967@yahoo.com.mx; Susana del Toro-Arreola* - susana@cucs.udg.mx

* Corresponding author

Published: 21 January 2008

BMC Cancer 2008, 8:16 doi:10.1/86/147|-2407-8-16
Received: II September 2007

Accepted: 21 January 2008

This article is available from: http://www.biomedcentral.com/I47/-2407/8/16

(C) 2008 Arreygue-Garcia et al; licensee BioMed Central Ltd.

This is an Open Access article distributed under the terms of the Creative Commons Attribution License (http://creativecommons.org/licenses/by/2.0), which permits unrestricted use, distribution, and reproduction in any medium, provided the original work is properly cited.

\begin{abstract}
Background: Cervical cancer is the second most common cancer in women worldwide. NK and cytotoxic $T$ cells play an important role in the elimination of virus-infected and tumor cells through NKG2D activating receptors, which can promote the lysis of target cells by binding to the major histocompatibility complex class I-related chain A (MICA) proteins. Increased serum levels of MICA have been found in patients with epithelial tumors. The aim of this study was to compare the levels of soluble MICA (sMICA) and NKG2D-expressing NK and T cells in blood samples from patients with cervical cancer or precursor lesions with those from healthy donors.

Methods: Peripheral blood with or without heparin was collected to obtain mononuclear cells or sera, respectively. Serum sMICA levels were measured by ELISA and NKG2D-expressing immune cells were analyzed by flow cytometry. Also, a correlation analysis was performed to associate sMICA levels with either NKG2D expression or with the stage of the lesion.

Results: Significant amounts of sMICA were detected in sera from nearly all patients. We found a decrease in the number of NKG2D-expressing NK and T cells in both cervical cancer and lesion groups when compared to healthy donors. Pearson analysis showed a negative correlation between sMICA and NKG2D-expressing T cells; however, we did not find a significant correlation when the analysis was applied to sMICA and NKG2D expression on NK cells.
\end{abstract}


Conclusion: Our results show for the first time that high sMICA levels are found in sera from patients with both cervical cancer and precursor lesions when compared with healthy donors. We also observed a diminution in the number of NKG2D-expressing NK and T cells in the patient samples; however, a significant negative correlation between sMICA and NKG2D expression was only seen in T cells.

\section{Background}

Cervical cancer is the second most common malignant tumor in women worldwide, and the most common tumor in developing countries including Mexico, the site of this study [1-3]. Infection with high-risk human papilloma virus (HPV) is considered the major etiological factor of HPV-related premalignant lesions and cervical cancer [4-7]. Virtually all cervical carcinoma patients (99.7\%) have shown to be HPV-DNA carriers [8]. Although HPV prevalence is very common in sexually active women [9], the infection in the majority of cases is transient, clearing in a short period of time without progression to clinical lesions [10-12]. In a minority of cases, HPV presence is established as a persistent infection. It is thought that viral persistence leads to progression from low-grade squamous intraepithelial lesions (LSIL) to high-grade squamous intraepithelial lesions (HSIL) and eventually to invasive carcinoma [13-16]. The progression of the lesions may involve an adverse tumor environment, wherein the mucosal immune response may be unable to eradicate malignant cells.

The innate immune response is considered to be the first line of defense at mucosal surfaces. NK cells are an important arm of the innate immune system specialized for killing virus-infected and tumor cells [17]. The activity of NK cells is tightly regulated by a complex balance of inhibitory and activating receptors [18]. NKG2D is a C-type lectin-like activating receptor encoded within the NK gene complex on human chromosome 12 [19]. NKG2D is expressed in almost all NK cells and a variety of T cell subsets such as CD8 ${ }^{+}$T cells [20]. NKG2D can promote tumor lysis by binding to a recently identified family of cell surface ligands encoded by the MHC class I chain-related (MIC) genes [21-23]. MIC proteins are a novel family of non-classical MHC class I molecules. The MIC family includes MICA, which is a highly polymorphic functional cell-surface protein [24]. Similar to classical HLA class I molecules, MICA also contains three extracellular domains ( $\alpha 1-\alpha 3)$; however, MICA neither associates with $\beta_{2}$-microglobulin nor binds antigen peptides. Under normal physiological conditions, MICA expression is almost restricted to the gastrointestinal epithelium $[25,26]$; nevertheless, MICA is overexpressed in several epithelial tumors [27-30]. This finding has led to the proposal that MICA is a stress cell marker in nascent epithelial tumors [26].
Available evidence suggests that NKG2D engagement by MICA induces proliferation, survival, and, cytotoxic activity in NK cells [31,32]. Consequently, NKG2D/MICA interaction may represent an important activation pathway to trigger the immune attack against tumor cells [30,33]. However, it has been demonstrated that MICA shedding from tumor cell surface occurs in a variety of malignant epithelial tumors, including advanced hepatocellular carcinoma, colon, prostate, renal, and breast cancer, as well as hematopoietic tumors [34-38]. Accumulation of sMICA in serum may lead to the downmodulation of NKG2D through the facilitation of NKG2D internalization and lysosomal degradation. This strategy has been proposed to be a novel mechanism used by cancer cells to evade the tumor immunosurveillance [39].

In this study, we formulated the hypothesis that sMICA levels increase concomitantly with the natural history of cervical cancer in the progression from intraepithelial precursor lesion to invasive cancer. To address this assertion, we compared the sMICA levels and the number of NKG2D-expressing NK and T cells in blood samples from patients with cervical cancer or precursor lesions with those from healthy donors. We also performed a correlation analysis to explore a relationship between sMICA levels and NKG2D expression. Furthermore, we associated sMICA levels with the stage of the lesion.

\section{Methods \\ Patients}

In accordance with the FIGO (International Federation of Gynecology and Obstetrics) System of Clinical Staging $[40,41]$, we included 10 patients with invasive squamous cell carcinoma of the uterine cervix and 17 patients with squamous intraepithelial lesion, which were classified as high-grade squamous intraepithelial lesion (HSIL) or low-grade squamous intraepithelial lesion (LSIL) following the 2001 Bethesda System for reporting cervical or vaginal cytologic diagnoses [42,43]. All patients enrolled in the study were first subjected to colposcopic evaluation. Ten age/gender matched healthy donors were also included as control group. All patients were attended at the Oncology and Gynecology Department, Hospital Civil de Guadalajara, Mexico. 
Peripheral blood (PB) samples were taken after written informed consent was obtained from all patients (LSIL, HSIL, and cervical cancer) and healthy donors. Samples were collected in heparinized tubes to separate peripheral blood mononuclear cells (PBMC). PB was also obtained without heparin in order to separate serum, which was stored at $-20^{\circ} \mathrm{C}$ until use.

\section{Ethical considerations}

The present study was approved by the Research Ethics Committee in Biomedical Sciences (Universidad de Guadalajara, Guadalajara, Jalisco, Mexico and Hospital Civil de Guadalajara, OPD, Guadalajara, Jalisco, Mexico. Trial reference: CSIM 200-22, 20000302032), in accordance with the guidelines of the Mexican Official Standard (Norma Oficial Mexicana NOM) and the World Medical Association Declaration of Helsinki (adopted by the $52^{\text {nd }}$ WMA General Assembly, Edinburgh, Scotland, October 2000).

\section{Quantification of sMICA in serum}

MICA ELISA kit (Immatics Biotechnologies, Tübingen, Germany) was used to detect sMICA in serum samples, according with the manufacturer protocol. Briefly, after covering the 96 well flat-bottom plates with capture antiMICA mAb, standard serial dilutions and serum samples were added to each well. Detection anti-MICA mAb was added to the wells. HRP-conjugated anti-mouse Ab (Southern Biotechnologies, Birmingham, AL, USA) was added and color was developed using tetramethylbenzidine system (KPL, Gaithersburg, MD, USA). Absorbance values (at $\mathrm{A}_{450}$ ) by duplicate were plotted against dilutions and expressed as $\mathrm{pg} / \mathrm{mL}$ (normalized to $\log _{10}$ ).

\section{NKG2D expression on NK and T cells}

Surface NKG2D expression was evaluated by flow cytometry. Briefly, PBMC were obtained by Ficoll-Hypaque density gradient centrifugation. After isolation, PBMC were adjusted at $8 \times 10^{5}$ cells $/ \mathrm{mL}$ and incubated with mouse anti-NKG2D primary mAb (kindly donated by Professor Alessandro Moretta, University of Genova, Italy) for 30 min at $4{ }^{\circ} \mathrm{C}$. Cells were washed with PBS and incubated with goat anti-mouse IgG FITC-conjugate as a secondary reagent for $30 \mathrm{~min}$ at $4^{\circ} \mathrm{C}$ in the dark. Afterward, cells were washed and incubated with PE-conjugated antiCD56, and PC5-conjugated anti-CD3 mAb; matching isotype controls were also included. Finally, cells were fixed with $0.5 \%$ paraformaldehyde solution. A three-color analysis on an EPICS XL-MCL Flow Cytometer (Beckman Coulter, Krefeld, Germany) was used to determine the NKG2D expression on CD56+CD3- and CD56-CD3 ${ }^{+}$populations.

\section{Statistical analysis}

Statistical analysis of all data was done using SPSS software version 10 (Chicago, IL, USA). The sMICA levels and percentages of NKG2D-expressing NK and T cells were expressed as mean \pm SD. Statistical comparisons among different groups were performed using a non-parametric test (Mann-Whitney test). Pearson analysis was performed to correlate sMICA levels with NKG2D expression and Spearman analysis was performed to correlate sMICA levels with the stage of the lesion. Additionally, a multivariate regression analysis was achieved to evaluate whether sMICA and NKG2D expression act in concert during the cervical cancer progression. For this analysis we used the method "forward stepwise" in which we added the independent variables (sMICA and NKG2D expression) one by one. A 95\% confidence interval $(p<0.05)$ was considered statistically significant.

\section{Results}

Ten patients with established histopathological diagnosis of uterine cervix invasive squamous cell carcinoma were enrolled in this study. Additionally, a group of 17 patients with squamous intraepithelial lesions was composed of 7 individuals diagnosed as high-grade and 10 individuals diagnosed as low grade. We also included a control group matched in age/gender as shown in Table 1. Clinical and laboratory parameters confirmed that patients and controls did not have any autoimmune or blood disorder that could alter our study variables (sMICA level and NKG2D expression).

\section{sMICA levels are preferentially augmented in patients with cervical cancer and precursor lesions}

We investigated the sMICA level in sera from cervical carcinoma patients and SIL patients (including both highgrade and low-grade lesions). Additionally, we also tested sMICA in healthy individuals. In order to normalize the sMICA values, we converted the data (expressed as $\mathrm{pg} / \mathrm{mL}$ ) to $\log _{10}$. As shown in Figure 1, we found significantly higher sMICA levels in patients with cervical cancer or precursor lesions when compared with healthy donors (Mann-Whitney test, $p<0.005$ in LSIL, $p<0.030$ in HSIL,

Table I: Patient characteristics

\begin{tabular}{cccc}
\hline $\begin{array}{c}\text { Study group } \\
\text { Age (years) }\end{array}$ & & $n$ \\
\hline Healthy donors & & 10 & $\begin{array}{c}27-52 \\
\text { SIL }\end{array}$ \\
& LSIL & 10 & $\begin{array}{c}\text { Median age }=38.4 \\
26-50\end{array}$ \\
& HSIL & 7 & $\begin{array}{c}\text { Median age }=36.6 \\
23-49 \\
\text { Carcinoma }\end{array}$ \\
& & 10 & $\begin{array}{c}\text { Median age }=35.0 \\
29-69 \\
\end{array}$ \\
& & & Median age $=45.4$ \\
\hline
\end{tabular}




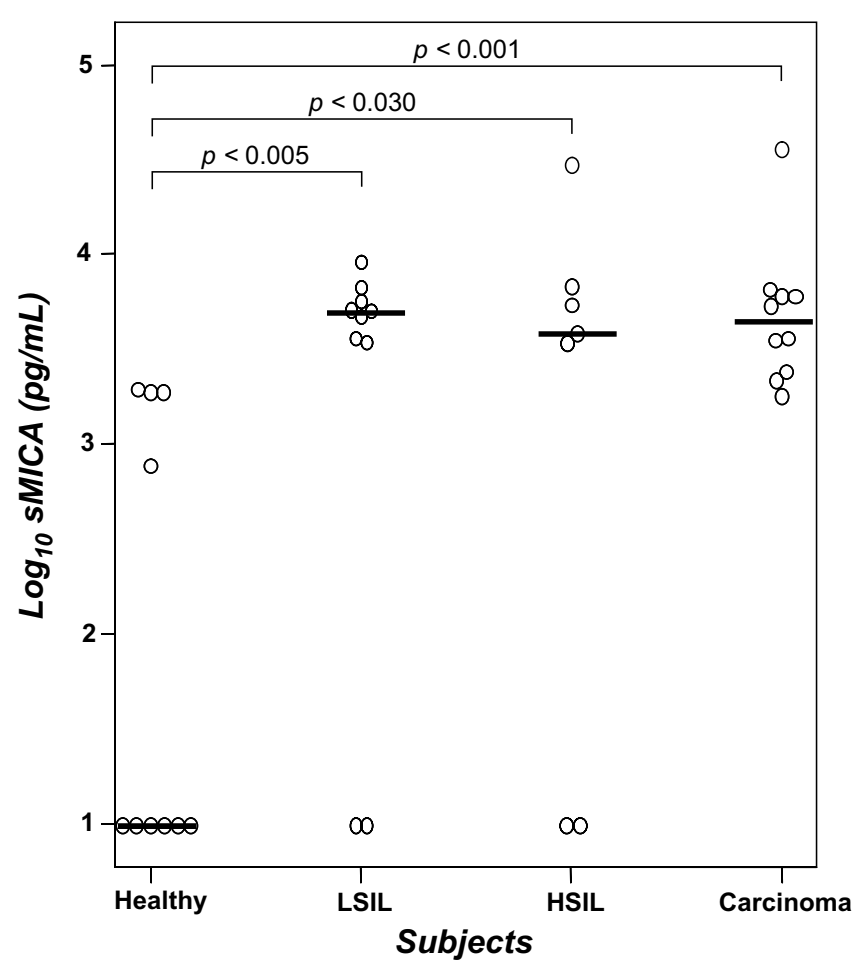

\section{Figure I}

Serum sMICA is elevated in cervical cancer patients. sMICA was determined by using ELISA assay. Short horizontal lines indicate the median value ( $\mathrm{pg} / \mathrm{mL}$ normalized to $\left.\log _{10}\right)$ in each group. Statistical analysis among all groups was performed by Mann-Whitney test.

and $p<0.001$ in cancer group). Interestingly, the majority of healthy individuals showed almost undetectable sMICA level (lower than $1 \mathrm{pg} / \mathrm{mL}$ ). In contrast, measurable sMICA level was found in patients with cervical cancer and precursor lesions. The highest sMICA level was found in the cancer group $(4.56 \mathrm{pg} / \mathrm{mL})$. We also examined a potential relationship between sMICA level and the stage of the lesion. Spearman correlation showed that sMICA level was significantly positively correlated with the severity of the lesion ( Rho $=0.519 ; p<0.001)$.

Reduced numbers of NKG2D-expressing NK and T cells in patients with cervical cancer and precursor lesions

NKG2D plays an important role in the immune recognition of tumor targets after engagement by MICA molecules [31,32]. Nevertheless, there is evidence showing that circulating sMICA interferes with NKG2D expression on NK and T cells [39]. Owing to the observed increase in the sMICA levels detected in sera from patients with cervical cancer and those with precursor lesions, we investigated expression of the NKG2D receptor on peripheral NK and T cells. First, we evaluated the percentage of NK and T cells in all patients and healthy donors. The results fell into the normal range in all groups, with a non-significant drop in cancer group (data not shown). In order to determine NKG2D expression on NK cells, we gated the CD56+CD3population. As shown in Figure 2A and Table 2, we found the following results: $50.40 \%$ of the gated population was NKG2D-positive in the control group, $28.57 \%$ in LSIL, $40.90 \%$ in HSIL and $27.49 \%$ in cancer group. Statistical comparison between the cancer and control groups revealed a significant difference $(p<0.034)$.

We also analyzed the $\mathrm{CD} 56^{-} \mathrm{CD}^{+}$population to determine NKG2D expression in $\mathrm{T}$ cells. We observed a decrease in the number of NKG2D-expressing T cells concordant with the severity of the lesion, as can be observed in Figure 2B and Table 2. The control group showed $24.80 \%$ of the gated population to be NKG2D-positive cells. In contrast, LSIL, HSIL, and cancer groups showed NKG2D positive percentages of $15.74,12.20$, and 8.28, respectively. Statistical analysis revealed a significant difference in both precursor lesion and cancer groups when compared to healthy individuals $(p<0.041, p<0.011$,

Table 2: NKG2D-expressing NK and T cells

\begin{tabular}{|c|c|c|c|c|c|c|c|c|}
\hline \multirow{3}{*}{ Subjects } & \multicolumn{8}{|c|}{ Percentage of NKG2D-expressing cells } \\
\hline & \multicolumn{4}{|c|}{ CD56+CD3- } & \multicolumn{4}{|c|}{ CD56-CD3+ } \\
\hline & $\begin{array}{c}\text { Mean } \\
\pm S D\end{array}$ & Min & $\operatorname{Max}$ & $p$ & $\begin{array}{l}\text { Mean } \\
\pm S D\end{array}$ & Min & Max & $p$ \\
\hline Healthy & $\begin{array}{c}50.40 \pm \\
20.78\end{array}$ & 21.44 & 83.84 & & $\begin{array}{c}24.80 \pm \\
7.67\end{array}$ & 17.30 & 40.20 & \\
\hline LSIL & $\begin{array}{c}28.57 \pm \\
1.36\end{array}$ & 3.60 & 78.40 & 0.010 & $\begin{array}{c}15.74 \pm \\
6.9 \mid\end{array}$ & 6.40 & 28.50 & 0.041 \\
\hline HSIL & $\begin{array}{c}40.90 \pm \\
5.67\end{array}$ & 2.70 & 88.10 & 0.495 & $\begin{array}{c}12.20 \pm \\
7.49\end{array}$ & 2.40 & 22.80 & 0.011 \\
\hline Invasive carcinoma & $\begin{array}{c}27.49 \pm \\
9.62\end{array}$ & 0.50 & 82.90 & 0.034 & $\begin{array}{c}8.28 \pm \\
0.25\end{array}$ & 0.10 & 29.60 & 0.005 \\
\hline
\end{tabular}

p represents the value obtained of comparing LSIL, HSIL, and carcinoma subjects vs healthy subjects 
A.

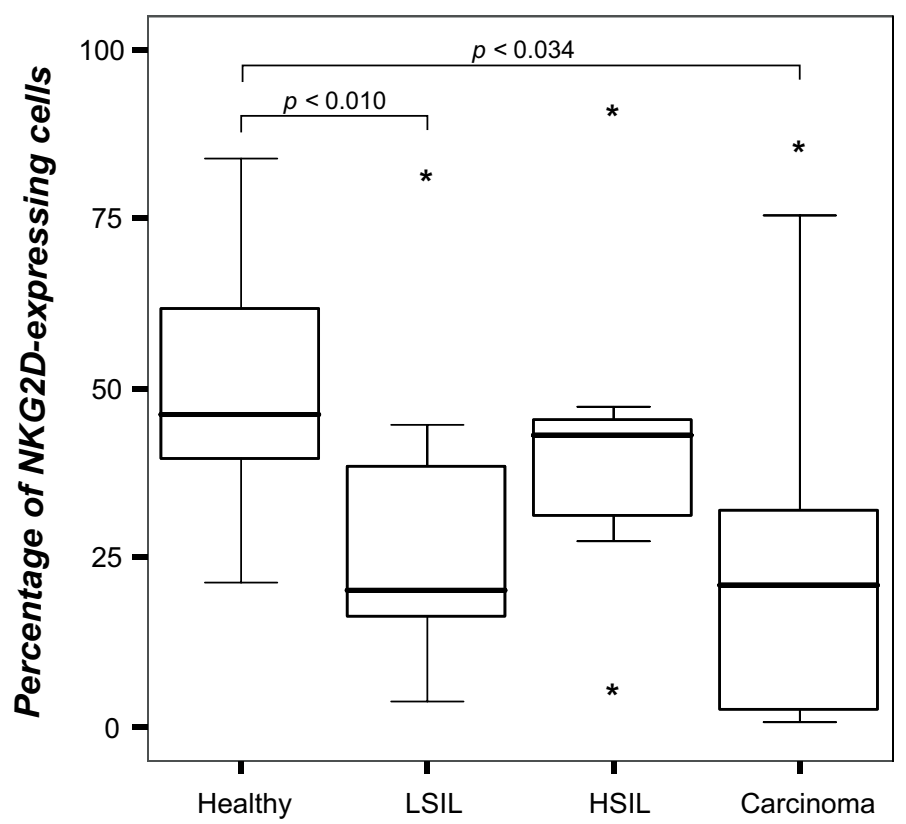

B.

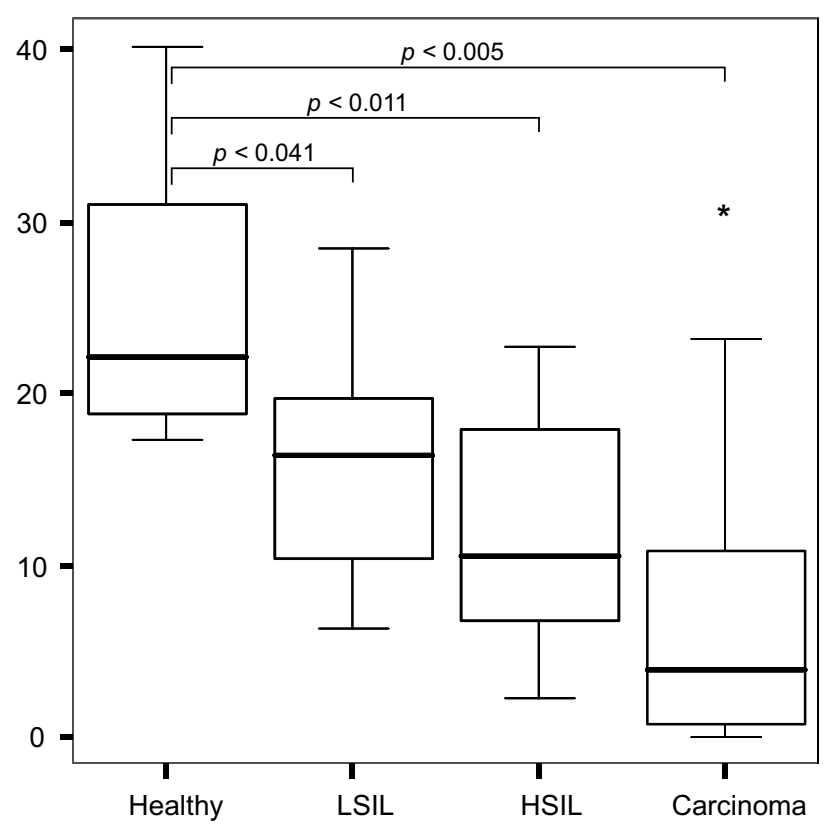

\section{Subjects}

Figure 2

NKG2D-expressing immune cells are decreased in patients with cervical cancer and precursor lesions. Three color flow cytometry analysis to detect CD3, CD56 and NKG2D was carried out on PBMC to determine the percentage of NKG2D-positive cells. A) NKG2D-expressing NK cells (CD56+CD3- population); B) NKG2D-expressing T cells (CD56-CD3 ${ }^{+}$population). The box plots represent each study group. Medians are represented as thick horizontal lines, $25^{\text {th }}$ and $75^{\text {th }}$ percentiles as boxes and $10^{\text {th }}$ and $90^{\text {th }}$ percentiles as whiskers. *Extreme values.

and $p<0.005$ to LSIL, HSIL, and cancer groups, respectively).

\section{Circulating sMICA can reduce the number of NKG2D- expressing $T$ cells}

It has been reported that sMICA in serum from patients with cancer induces down-modulation of surface NKG2D expression [39]. For this reason, we investigated a potential correlation between sMICA levels and the percentage of NKG2D-expressing NK and T cells. As shown in Figure 3, sMICA levels were negatively correlated with the number of NKG2D-expressing T cells ( $\mathrm{r}=-0.359 ; p<$ 0.015 ). In contrast, we did not observe any significant correlation between sMICA level and NKG2D-expressing NK cells (data not shown). It is important to mention that despite the lack of statistical correlation, we observed a substantial decrease of NKG2D-expressing NK cells in more than a half of the analyzed patients with cervical cancer. Figure 4 shows representative histograms and dot plots of NKG2D-expressing NK and T cells in all groups.

We used a multivariate regression analysis to determine whether increasing sMICA levels and decreasing NKG2D expression on $\mathrm{T}$ cells could act in concert to predict the progression of the lesion advancing toward cancer. The results derived from that analysis (Table 3) show that both categories (sMICA level and NKG2D) were significantly strongly related with the progression of the lesion $\left(\mathrm{R}^{2}=\right.$ $0.467 ; p<0.001)$. The importance of these results is that $\mathrm{R}^{2}$ explains $(46.7 \%)$ of the variation in the progression toward cancer.

\section{Discussion}

Recent reports have revealed a new tumor evasion strategy involving MICA release from malignant cell surface in different human tumors [34-37]. In this study we found significant sMICA levels in patients with cervical cancer. Proteolytic shedding has been proposed as the key mechanism by which MICA is released from the cell surface, similar to the cleavage occurring with other membranebound proteins. By using different protease inhibitors, it was elucidated that metalloproteinases were responsible for the cleavage of the MICA $\alpha 1 \alpha 2 \alpha 3$ extracellular domain from the cell surface in several tumor lines [44]. This finding may have implications to cervical cancer as previous data in our laboratory have shown extensive 


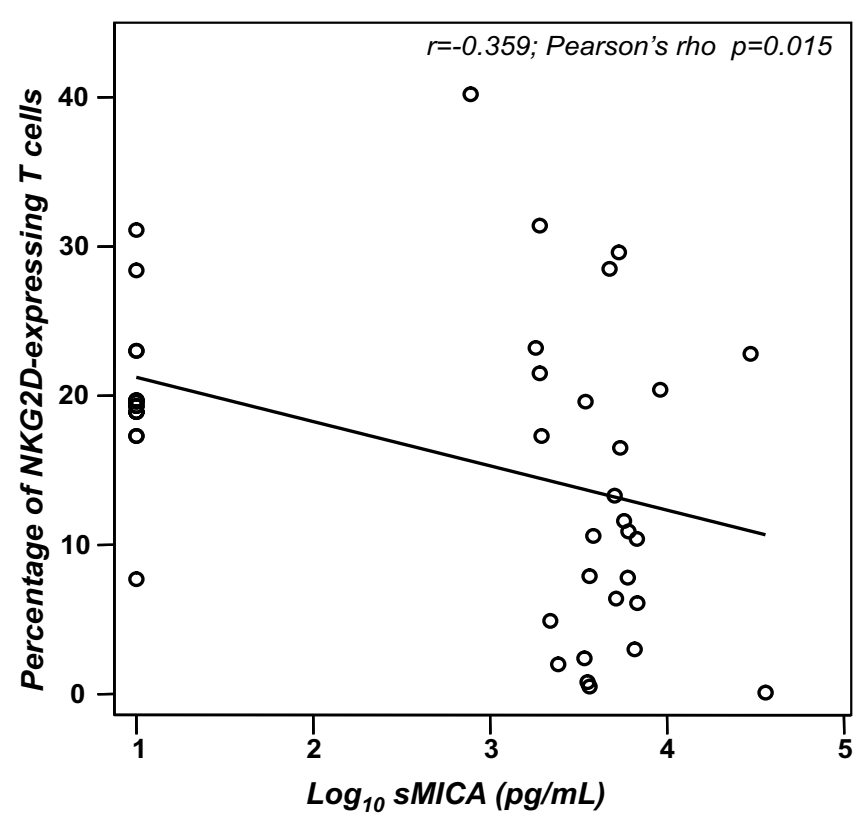

Figure 3

sMICA levels and the number of NKG2D-expressing T cells are negatively correlated. Correlation analysis was done using the Pearson test. Values are normalized as $\log _{10}$.

metalloproteinase activity in cervical tissue extracts from patients with cervical cancer and precursor lesions [45].

This suggests that metalloproteinases, aside from playing an important role in invasion, metastasis, and angiogenesis processes, may also have a role in allowing MICA shedding tumor cells to evade immune attack. However, we cannot discard the possibility that other different proteases are also participating in the cleavage of MICA as has been recently reported by Kaiser $e t$ al. In that report, the authors demonstrated that MICA shedding was facilitated by a disufide-isomerase interacting directly with MICA $\alpha 3$ [46]. Thus, it appears that different enzymes could be enabling tumor cells to escape from the immune attack. Since in this study we did not examine the relevance of the proteolytic activity, it will be of particular importance to characterize the enzymatic activity with respect to cell surface MICA shedding in cervical cancer.

We observed higher levels of sMICA in patients with lowgrade intraepithelial lesions in comparison with healthy individuals; these levels increased in accordance with cancer progression. This finding is in agreement with recent results obtained by $\mathrm{Wu}$ et al., who detected elevated amounts of sMICA in patients with prostate cancer [36]. Moreover, significantly higher levels were seen in patients with more advanced diseases, suggesting that the MICA shedding may contribute to prostate cancer progression Thus, consistent with Wu et al., we could speculate that high levels of circulating sMICA that we observed may be contributing to the immune tolerance observed in patients with cervical cancer. However, functional experiments to elucidate the actual relevance of MICA/NKG2D pathway in cervical cancer will be necessary.

Different studies have proven the down-modulation of HLA class I expression during cervical cancer progression $[47,48]$. Hence, it is feasible to assume that NK cells may represent an important immune defense against cervical cancer. Different activating receptors confer to NK cells the capacity to kill virus-infected or tumor cells $[49,50]$; one of these receptors is represented by NKG2D, which can recognize different ligands including MICA molecules; thus, NKG2D could have a significant role in antitumor immune response [21-23].

Recently, Doubrovina et al., have established that MICA in serum from patients with colon adenocarcinoma downmodulates NKG2D expression on NK cells via its internalization and subsequent lysosomal degradation [35]. Importantly, we observed a reduction of NKG2D-expressing NK cells in patients with cervical cancer and precursor lesions; however, we did not find a significant statistical correlation between sMICA and lower NKG2D expression on these cells. These results indicate that additional factors could be also affecting the surface NKG2D expression. Lee et al., have provided evidence showing that TGF$\beta 1$ present in plasma of lung and colorectal cancer patients impairs NK cell activity via NKG2D down-modulation [51]. Using a technology to silence TGF- $\beta 1$ and $-\beta 2$ genes in malignant glioma cells, Friese et al. revealed that these tumor cells did not down-modulate the NKG2D expression on NKL cells (a NK cell line); moreover, strong surface MICA expression on tumor cells was also observed when they blocked the TGF- $\beta$ production promoting a strong recognition by immune cells [52]; these results support the key role of TGF- $\beta$ in the MICA/NKG2D pathway. It is well known that this cytokine is largely produced by many tumor cells and it is also common in cervical squamous intraepithelial lesions [53]. For instance, it has been shown that HPV-11 transformed human tissue overexpresses TGF- $\beta 1$ [54] and benign cervical lesions, particularly, have been associated with HPV-6 or -11 .

It has been recently observed that NKp44, another important receptor confined only to activated NK cells, becomes down-modulated on NK cells from both healthy donors and patients with cancer upon exposure to sMICA-containing serum [35]. Taking into account that both NKG2D and NKp44 on the cell surface may be down-modulated by sMICA, it is viable to consider that circulating sMICA could be affecting the integration of different crucial triggering signals in NK cells. Collectively, these alterations 

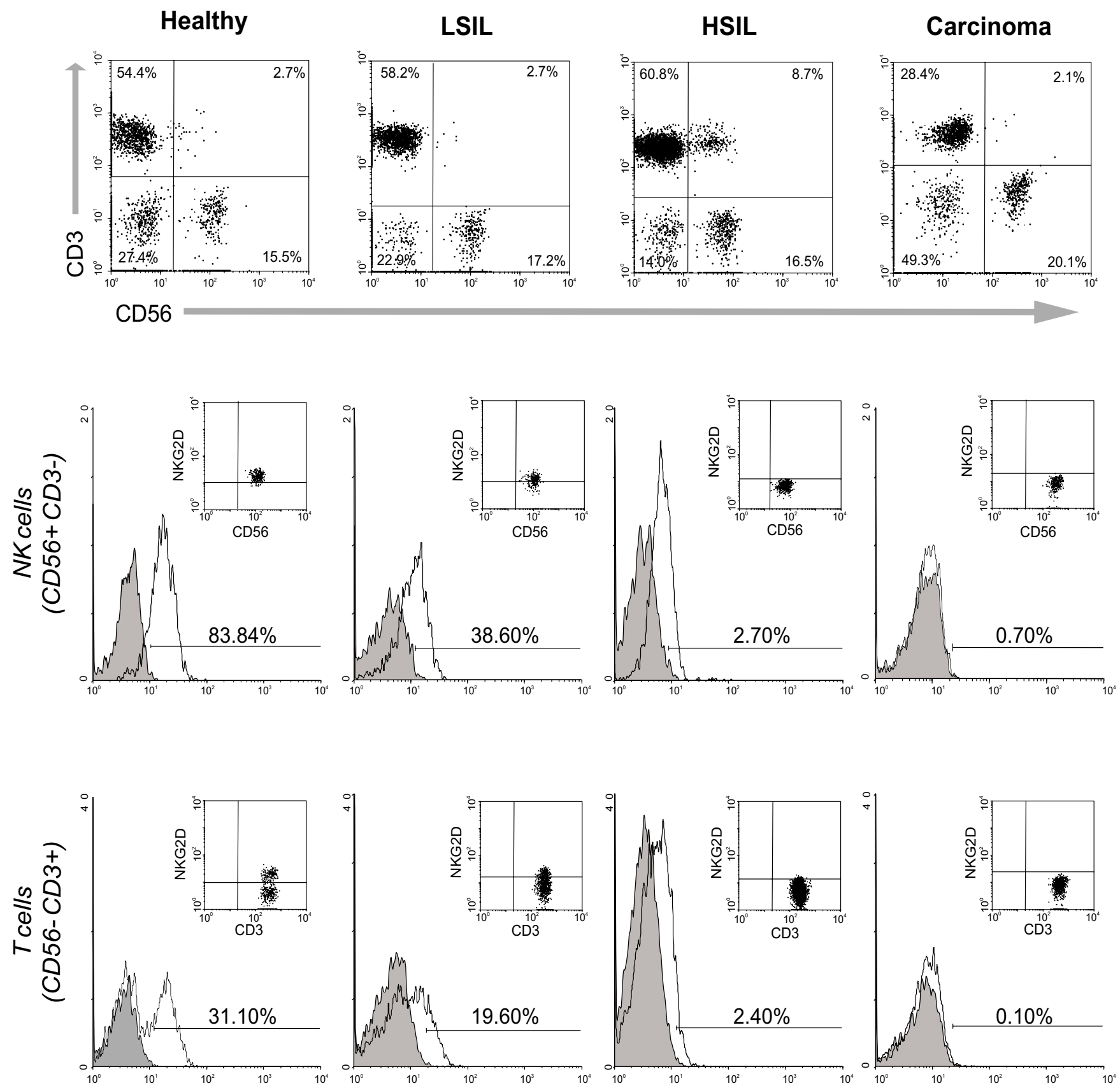

Figure 4

The number of NKG2D-expressing NK and T cells diminishes during cervical cancer progression. NKG2D expression was measured using flow cytometry while gating on CD56+CD3- (NK cell) and CD56-CD3 ${ }^{+}$(T cell) populations. The histograms and dot plots show the results obtained from a representative individual of each group. The same tendency is observed in both NK and T cells (filled curve: isotype control Ab, open curve: anti-NKG2D).

may be contributing to the incomplete NK cell-mediated cytotoxic function in patients with cancer.

NKG2D expression is not only confined to NK cells, but it is also expressed on $\mathrm{CD} 8^{+}$cytotoxic $\mathrm{T}$ cells, where this receptor confers co-stimulatory signals [55]. Moreover,
NKG2D expression has also been described in a subset of CD4 ${ }^{+} \mathrm{T}$ cells from patients with some inflammatory diseases [56]. For this reason, we also evaluated surface NKG2D expression on T cells and analyzed its correlation with sMICA level. Despite finding a statistically significant correlation between sMICA level and NKG2D-expression, 
Table 3: Multivariate regression analysis of sMICA and NKG2D-expressing $T$ cells acting in concert in the progression of the lesion

\begin{tabular}{|c|c|c|c|c|c|c|c|}
\hline & \multicolumn{2}{|c|}{ Regression coefficients } & \multirow{2}{*}{$\begin{array}{c}\begin{array}{c}\text { Standardized } \\
\text { coefficient }\end{array} \\
\text { Beta }\end{array}$} & \multirow[b]{2}{*}{$t$} & \multirow[b]{2}{*}{ Sig. } & \multicolumn{2}{|c|}{$95 \%$ C.I. for B } \\
\hline & B & SEM for $B$ & & & & Lower limit & Upper limit \\
\hline Constant & 2.417 & 0.532 & & 4.544 & 0.000 & 1.336 & 3.497 \\
\hline $\log _{10} \mathrm{sMICA}$ & 0.314 & 0.128 & 0.330 & 2.460 & 0.019 & 0.055 & 0.574 \\
\hline $\begin{array}{l}\text { \% NKG2D- } \\
\text { expressing T } \\
\text { cells }\end{array}$ & -0.057 & 0.015 & -0.492 & -3.667 & 0.001 & -0.088 & -0.025 \\
\hline
\end{tabular}

B: regression coefficient in the equation which predicts the grade of the lesion considering to both sMICA and NKG2D expression as independent variables; SEM for B: standard error for the regression coefficients; Beta: standardized regression coefficient which determines the actual weight of the regression coefficient if all variables are expressed in standard units; $\mathbf{t}$ : $t$-test value for the regression coefficient; sig: $p$ value $\left(\mathbf{R}^{\mathbf{2}}=\mathbf{0 . 4 6 7} ; \mathbf{p}\right.$ $<0.001$ ).

our analysis only showed a weak correlation, which suggests the existence of additional factors that, in concert with sMICA, could promote the NKG2D down-modulation; one of such factors could be TGF- $\beta 1$ as previously mentioned. In contrast to the several reports supporting the role of sMICA in the NKG2D down-modulation [39], there is a recent report by Osaki $e t$ al., which showed that sMICA levels were not different between gastric cancer patients and normal controls, indicating that sMICA was not responsible for inducing the NKG2D down-modulation on $\mathrm{CD} 8^{+} \mathrm{T}$ cells from those patients. However, transwell experiments demonstrated that direct contact between $\mathrm{CD}^{+} \mathrm{T}$ cells and MICA-expressing tumor cells caused NKG2D down-modulation, indicating that surface MICA was responsible for that defect [57]. Independent of its form (sMICA or membrane MICA), it is clear that this molecule promotes, in part at least, the NKG2D downmodulation in immune cells. Since in this study we only used an anti-CD3 antibody, we were not able to distinguish between NKG2D-expressing $\mathrm{CD}^{+}$or $\mathrm{CD} 4{ }^{+} \mathrm{T}$ cells; thus, this methodological flaw could also explain the weak correlation seen between sMICA level and NKG2Dexpressing T cells. Therefore, the analysis to distinguish $\mathrm{CD}^{+}$or $\mathrm{CD} 4^{+} \mathrm{T}$ cells would have been more interesting and meaningful that our present results, which were confined to the total $\mathrm{T}$ cell population. Future studies are planned to identify the actual $\mathrm{T}$ cell population in which cell surface NKG2D is being affected. Consequently, it will be possible to discern if specific $\mathrm{T}$ cell lineages fail to be fully activated in patients with HPV-associated cervical lesions.

In this study we have demonstrated a reduction in the number of NKG2D-expressing immune cells. At the moment, we do not know the meaning of this finding; however, we consider that this reduction was not because a total lack of surface NKG2D, due to the flow cytometry analysis did not reveal the presence of more than a peak in the histograms (Figure 4). We cannot discard the possibility that the reduction in the number of NKG2D- expressing cells could be attributed to cell death. In this study we did not examine apoptosis in NK or T cells, and we also did not look for sMICA bound to the NKG2D receptor; therefore, we cannot know if a sMICA-induced apoptosis mechanism in immune cells exists in patients with cervical cancer and precursor lesions. The above phenomenon has been reported with non-classical HLA molecules, such as HLA-G, which has multiple immunoregulatory properties, mainly exemplified in the abrogation of maternal NK cell activity [58]. This molecule is expressed not only as a cell surface molecule, but also as a soluble form which has been found in sera from patients undergoing different malignancies [59-61]. Interestingly, soluble isoforms of HLA-G have shown to trigger in vitro apoptosis in both activated $\mathrm{CD} 8{ }^{+}$cytotoxic $\mathrm{NK}$ and $\mathrm{T}$ cells through a Fas/FasL mechanism $[62,63]$. In consequence, this immunoregulatory role used by secreted forms of HLA-G could represent an additional mechanism by which tumors avoid the immune surveillance. Therefore, it will be interesting to investigate if soluble HLA-G is present in cervical cancer patients and especially, to examine if serum HLA-G and MICA altogether are able to deliver a death signal in immune cells.

Finally, the results derived from the multivariate regression analysis statistically show that an increase in sMICA level may be associated with progression to invasive cancer; while an increase of NKG2D-expressing T cells could be negatively correlated with cancer progression. We did not find any significant correlation when we extended the same analysis to NKG2D-expressing NK cells. Thus, it will be interesting to design functional experiments to test whether T cells are being affected by sMICA, even more, it will be necessary to study separately $\mathrm{CD} 4^{+}$and $\mathrm{CD} 8^{+} \mathrm{T}$ cells to discern their actual correlation with sMICA.

\section{Conclusion}

Our study reveals for the first time that sMICA is elevated in patients with cervical cancer and precursor lesions. We also demonstrated a reduced number of NKG2D-express- 
ing NK and T cells in patient samples. Furthermore, a significant correlation between sMICA and NKG2D expression was found in T cells, but not in NK cells. If confirmed that sMICA is directly contributing to the immune evasion present in patients with cancer, targeting specific proteases involved in MICA shedding from cell surfaces or directly blocking sMICA in circulation could be a clinically important strategy to boost the anti-tumor response against cervical cancer.

\section{Competing interests}

The author(s) declare that they have no competing interests.

\section{Authors' contributions}

NAG performed the experimental work described in the study, searched scientific literature, contributed with the draft and edited the manuscript; ADN contributed to the planning of the project; participated in its coordination and provided valuable scientific suggestions; ATA was the core in the flow cytometry experiments and performed research; ACA participated in the design of the study and contributed to the review of the manuscript; OGR contributed to the draft of the manuscript and helped with editing; LJS, and AAL oversaw the experiments, contributed with scientific ideas and assisted with the writing; RTS supported with the statistical analysis of the data; VDR, and TGI helped in the ELISA experiments; $\mathrm{ABC}$ and GHF contributed with scientific ideas and research; STA conceived and designed the theoretical framework of the study, provided scientific guidance throughout the project and wrote the manuscript. All authors read and approved the final manuscript.

\section{Acknowledgements}

We are indebted to Jesse Haramati of University of California, Santa Cruz for critical commentary and proofreading of the manuscript. The project was partly financed under grant support from the Terry Fox Foundation.

\section{References}

I. Boyle P: Global burden of cancer. Lancet 1997, 349 Suppl 2:SII23-6.

2. Sankaranarayanan R, Ferlay J: Worldwide burden of gynaecological cancer: the size of the problem. Best Pract Res Clin Obstet Gynaecol 2006, 20(2):207-225.

3. Lazcano-Ponce EC, Moss S, Alonso de Ruiz P, Salmeron Castro J, Hernandez Avila M: Cervical cancer screening in developing countries: why is it ineffective? The case of Mexico. Arch Med Res 1999, 30(3):240-250.

4. zur Hausen H: Papillomavirus infections--a major cause of human cancers. Biochim Biophys Acta 1996, I 288(2):F55-78.

5. Munoz N: Human papillomavirus and cancer: the epidemiological evidence. J Clin Virol 2000, I 9( I-2): I-5

6. Bosch FX, Lorincz A, Munoz N, Meijer CJ, Shah KV: The causal relation between human papillomavirus and cervical cancer. J Clin Pathol 2002, 55(4):244-265.

7. Clifford GM, Smith JS, Plummer M, Munoz N, Franceschi S: Human papillomavirus types in invasive cervical cancer worldwide: a meta-analysis. Br J Cancer 2003, 88(I):63-73.

8. Walboomers JM, Jacobs MV, Manos MM, Bosch FX, Kummer JA, Shah KV, Snijders PJ, Peto J, Meijer CJ, Munoz N: Human papillomavirus is a necessary cause of invasive cervical cancer worldwide. J Pathol 1999, 189(1): I2-19.

9. Richardson H, Kelsall G, Tellier P, Voyer H, Abrahamowicz M, Ferenczy A, Coutlee F, Franco EL: The natural history of type-specific human papillomavirus infections in female university students. Cancer Epidemiol Biomarkers Prev 2003, I 2(6):485-490.

10. Ho GY, Bierman R, Beardsley L, Chang CJ, Burk RD: Natural history of cervicovaginal papillomavirus infection in young women. N Engl J Med 1998, 338(7):423-428.

II. Sellors JW, Karwalajtys TL, Kaczorowski J, Mahony JB, Lytwyn A, Chong S, Sparrow J, Lorincz A: Incidence, clearance and predictors of human papillomavirus infection in women. Cmaj 2003, I 68(4):42I-425.

12. Richardson H, Abrahamowicz M, Tellier PP, Kelsall G, du Berger R, Ferenczy A, Coutlee F, Franco EL: Modifiable risk factors associated with clearance of type-specific cervical human papillomavirus infections in a cohort of university students. Cancer Epidemiol Biomarkers Prev 2005, I 4(5): I | 49- I I 56.

13. Dalstein V, Riethmuller D, Pretet JL, Le Bail Carval K, Sautiere JL, Carbillet JP, Kantelip B, Schaal JP, Mougin C: Persistence and load of high-risk HPV are predictors for development of high-grade cervical lesions: a longitudinal French cohort study. Int J Cancer 2003, 106(3):396-403.

14. Cuschieri KS, Cubie HA, Whitley MW, Gilkison G, Arends MJ, Graham C, McGoogan E: Persistent high risk HPV infection associated with development of cervical neoplasia in a prospective population study. J Clin Pathol 2005, 58(9):946-950.

15. Snijders PJ, Steenbergen RD, Heideman DA, Meijer CJ: HPV-mediated cervical carcinogenesis: concepts and clinical implications. J Pathol 2006, 208(2): I52-164.

16. Brummer O, Hollwitz B, Bohmer G, Kuhnle H, Petry KU: Human papillomavirus-type persistence patterns predict the clinical outcome of cervical intraepithelial neoplasia. Gynecol Oncol 2006.

17. Smyth MJ, Cretney E, Kelly JM, Westwood JA, Street SE, Yagita H, Takeda K, van Dommelen SL, Degli-Esposti MA, Hayakawa Y: Activation of NK cell cytotoxicity. Mol Immunol 2005, 42(4):50 I-5 I 0.

18. Moretta L, Bottino C, Pende D, Castriconi R, Mingari MC, Moretta A: Surface NK receptors and their ligands on tumor cells. Semin Immunol 2006, I 8(3): I5I-I58.

19. Glienke J, Sobanov Y, Brostjan C, Steffens C, Nguyen C, Lehrach H, Hofer E, Francis F: The genomic organization of NKG2C, E, F, and $D$ receptor genes in the human natural killer gene complex. Immunogenetics 1998, 48(3): I63-I73.

20. Jamieson AM, Diefenbach A, McMahon CW, Xiong N, Carlyle JR, Raulet DH: The role of the NKG2D immunoreceptor in immune cell activation and natural killing. Immunity 2002, I 7(I): 19-29.

21. Diefenbach A, Jensen ER, Jamieson AM, Raulet DH: Rae I and $\mathbf{H 6 0}$ ligands of the NKG2D receptor stimulate tumour immunity. Nature 200I, 4I3(6852): I65-I7I.

22. Pende D, Rivera P, Marcenaro S, Chang CC, Biassoni R, Conte R, Kubin M, Cosman D, Ferrone S, Moretta L, Moretta A: Major histocompatibility complex class I-related chain A and ULI6binding protein expression on tumor cell lines of different histotypes: analysis of tumor susceptibility to NKG2D. dependent natural killer cell cytotoxicity. Cancer Res 2002, 62(2I):6178-6186.

23. Carbone E, Neri P, Mesuraca M, Fulciniti MT, Otsuki T, Pende D, Groh V, Spies T, Pollio G, Cosman D, Catalano L, Tassone P, Rotoli $B$, Venuta S: HLA class I, NKG2D, and natural cytotoxicity receptors regulate multiple myeloma cell recognition by natural killer cells. Blood 2005, I 05(I):25I-258.

24. Robinson J, Perez-Rodriguez M, Waller MJ, Cuillerier B, Bahram S, Yao Z, Albert ED, Madrigal JA, Marsh SG: MICA sequences 2000. Immunogenetics 200I, 53(2): I 50-169.

25. Bahram S, Bresnahan M, Geraghty DE, Spies T: A second lineage of mammalian major histocompatibility complex class I genes. Proc Natl Acad Sci U S A 1994, 9 I( I 4):6259-6263.

26. Groh V, Bahram S, Bauer S, Herman A, Beauchamp M, Spies T: Cell stress-regulated human major histocompatibility complex class I gene expressed in gastrointestinal epithelium. Proc Natl Acad Sci U S A 1996, 93(22): I 2445- 12450.

27. Vetter CS, Groh V, thor Straten P, Spies T, Brocker EB, Becker JC: Expression of stress-induced MHC class I related chain mol- 
ecules on human melanoma. I Invest Dermatol 2002, I I 8(4):600-605

28. Groh V, Rhinehart R, Secrist H, Bauer S, Grabstein KH, Spies T: Broad tumor-associated expression and recognition by tumor-derived gamma delta T cells of MICA and MICB. Proc Natl Acad Sci U S A 1999, 96( I 2):6879-6884.

29. Jinushi M, Takehara T, Tatsumi T, Kanto T, Groh V, Spies T, Kimura R, Miyagi T, Mochizuki K, Sasaki Y, Hayashi N: Expression and role of MICA and MICB in human hepatocellular carcinomas and their regulation by retinoic acid. Int J Cancer 2003, 104(3):354-36I.

30. Watson NF, Spendlove I, Madjd Z, McGilvray R, Green AR, Ellis IO, Scholefield JH, Durrant LG: Expression of the stress-related MHC class I chain-related protein MICA is an indicator of good prognosis in colorectal cancer patients. Int J Cancer 2006 I I 8(6): | $445-1452$.

31. Pende D, Cantoni C, Rivera P, Vitale M, Castriconi R, Marcenaro S, Nanni M, Biassoni R, Bottino C, Moretta A, Moretta L: Role of NKG2D in tumor cell lysis mediated by human NK cells: cooperation with natural cytotoxicity receptors and capability of recognizing tumors of nonepithelial origin. Eur J Immunol 200I, 3 I(4): I076-1086

32. Moretta A, Bottino C, Vitale M, Pende D, Cantoni C, Mingari MC Biassoni R, Moretta $L$ : Activating receptors and coreceptors involved in human natural killer cell-mediated cytolysis. Annu Rev Immunol 200I, 19:197-223.

33. Bauer S, Groh V, Wu J, Steinle A, Phillips JH, Lanier LL, Spies T: Activation of NK cells and T cells by NKG2D, a receptor for stress-inducible MICA. Science 1999, 285(5428):727-729.

34. Jinushi $M$, Takehara $T$, Tatsumi $T$, Hiramatsu N, Sakamori $R$, Yamaguchi S, Hayashi N: Impairment of natural killer cell and dendritic cell functions by the soluble form of MHC class Irelated chain $A$ in advanced human hepatocellular carcinomas. I Hepatol 2005, 43(6): $1013-1020$

35. Doubrovina ES, Doubrovin MM, Vider E, Sisson RB, O'Reilly RJ, Dupont B, Vyas YM: Evasion from NK cell immunity by MHC class I chain-related molecules expressing colon adenocarcinoma. J Immunol 2003, I I I ( 2):6891-6899.

36. Wu JD, Higgins LM, Steinle A, Cosman D, Haugk K, Plymate SR Prevalent expression of the immunostimulatory MHC class I chain-related molecule is counteracted by shedding in prostate cancer. / Clin Invest 2004, I I 4(4):560-568.

37. Holdenrieder S, Stieber P, Peterfi A, Nagel D, Steinle A, Salih HR: Soluble MICA in malignant diseases. Int J Cancer 2006 I I 8(3):684-687.

38. Salih HR, Antropius H, Gieseke F, Lutz SZ, Kanz L, Rammensee HG, Steinle A: Functional expression and release of ligands for the activating immunoreceptor NKG2D in leukemia. Blood 2003, 102(4): $1389-1396$.

39. Groh V, Wu J, Yee C, Spies T: Tumour-derived soluble MIC ligands impair expression of NKG2D and T-cell activation. Nature 2002, 419(6908):734-738.

40. Creasman WT: New gynecologic cancer staging. Gynecol Oncol 1995, 58(2): $157-158$

41. Moore DH: Cervical cancer. Obstet Gynecol 2006, 107(5): I1 152-1161.

42. Solomon D, Davey D, Kurman R, Moriarty A, O'Connor D, Prey M, Raab S, Sherman M, Wilbur D, Wright T Jr., Young N: The 200 Bethesda System: terminology for reporting results of cervical cytology. Jama 2002, 287(16):2। I4-21। 9.

43. Crothers BA: The Bethesda System 200I: update on terminology and application. Clin Obstet Gynecol 2005, 48(I):98-I07.

44. Salih HR, Rammensee HG, Steinle A: Cutting edge: down-regulation of MICA on human tumors by proteolytic shedding. J Immunol 2002, 169(8):4098-4102.

45. Daneri-Navarro A, Del Toro-Arreola S, Bravo-Cuellar A, Cabrera N, Orbach-Arbouys S, Perez-Montfort R: Proteolytic activity in extracts of invasive cervical carcinoma and precursor lesions. Biomed Pharmacother 1995, 49(6):304-310.

46. Kaiser BK, Yim D, Chow IT, Gonzalez S, Dai Z, Mann HH, Strong RK, Groh V, Spies T: Disulphide-isomerase-enabled shedding of tumour-associated NKG2D ligands. Nature 2007, 447(7 I 43): 482-486.

47. Torres LM, Cabrera T, Concha A, Oliva MR, Ruiz-Cabello F, Garrido F: HLA class I expression and HPV-16 sequences in premalig- nant and malignant lesions of the cervix. Tissue Antigens 1993, 4I(2):65-7I.

48. Ryu KS, Lee YS, Kim BK, Park YG, Kim YW, Hur SY, Kim TE, Kim IK, Kim JW: Alterations of HLA class I and II antigen expression in preinvasive, invasive and metastatic cervical cancers. Exp Mol Med 200I, 33(3): I36-I 44.

49. Lanier LL: NK cell receptors. Annu Rev Immunol 1998, 16:359-393.

50. Lanier LL: NK cell recognition. Annu Rev Immunol 2005, 23:225-274.

51. Lee JC, Lee KM, Kim DW, Heo DS: Elevated TGF-beta I secretion and down-modulation of NKG2D underlies impaired NK cytotoxicity in cancer patients. I Immunol 2004, I72(12):7335-7340.

52. Friese MA, Wischhusen J, Wick W, Weiler M, Eisele G, Steinle A, Weller M: RNA interference targeting transforming growth factor-beta enhances NKG2D-mediated antiglioma immune response, inhibits glioma cell migration and invasiveness, and abrogates tumorigenicity in vivo. Cancer Res 2004, 64(20):7596-7603.

53. Tervahauta A, Syrjanen S, Yliskoski M, Gold LI, Syrjanen K: Expression of transforming growth factor-beta $I$ and -beta 2 in human papillomavirus (HPV)-associated lesions of the uterine cervix. Gynecol Oncol 1994, 54(3):349-356.

54. Shier MK, Neely EB, Ward MG, Richards ME, Manders EC, Meyers C, Howett MK: Correlation of TGF beta I overexpression with down-regulation of proliferation-inducing molecules in HPV. II transformed human tissue xenografts. Anticancer Res 1999, I 9(6B):4969-4976.

55. Verneris MR, Karami M, Baker J, Jayaswal A, Negrin RS: Role of NKG2D signaling in the cytotoxicity of activated and expanded CD8+ T cells. Blood 2004, 103(8):3065-3072.

56. Allez M, Tieng V, Nakazawa A, Treton X, Pacault V, Dulphy N, CaillatZucman S, Paul P, Gornet JM, Douay C, Ravet S, Tamouza R, Charron $D$, Lemann M, Mayer L, Toubert A: CD4+NKG2D+ T cells in Crohn's disease mediate inflammatory and cytotoxic responses through MICA interactions. Gastroenterology 2007, I 32(7):2346-2358.

57. Osaki T, Saito H, Yoshikawa T, Matsumoto S, Tatebe S, Tsujitani S, lkeguchi M: Decreased NKG2D expression on CD8+ T cell is involved in immune evasion in patients with gastric cancer. Clin Cancer Res 2007, I 3 (2 Pt I):382-387.

58. Hunt JS, Petroff MG, Mclntire RH, Ober C: HLA-G and immune tolerance in pregnancy. Faseb J 2005, I 9(7):68I-693.

59. Ugurel S, Rebmann V, Ferrone S, Tilgen W, Grosse-Wilde H, Reinhold $U$ : Soluble human leukocyte antigen--G serum level is elevated in melanoma patients and is further increased by interferon-alpha immunotherapy. Cancer 200I, 92(2):369-376.

60. Rebmann V, Regel J, Stolke D, Grosse-Wilde H: Secretion of sHLA-G molecules in malignancies. Semin Cancer Biol 2003, I3(5):37|-377.

6I. Morandi F, Levreri I, Bocca P, Galleni B, Raffaghello L, Ferrone S, Prigione I, Pistoia V: Human neuroblastoma cells trigger an immunosuppressive program in monocytes by stimulating soluble HLA-G release. Cancer Res 2007, 67( I 3):6433-644I.

62. Fournel S, Aguerre-Girr M, Huc X, Lenfant F, Alam A, Toubert A, Bensussan A, Le Bouteiller P: Cutting edge: soluble HLA-G I triggers CD95/CD95 ligand-mediated apoptosis in activated CD8+ cells by interacting with CD8. I Immunol 2000, I64(I2):6100-6104.

63. Contini P, Ghio M, Poggi A, Filaci G, Indiveri F, Ferrone S, Puppo F: Soluble HLA-A,-B,-C and -G molecules induce apoptosis in $T$ and NK CD8+ cells and inhibit cytotoxic $T$ cell activity through CD8 ligation. Eur J Immunol 2003, 33(I): I25-I34.

\section{Pre-publication history}

The pre-publication history for this paper can be accessed here:

http://www.biomedcentral.com/1471-2407/8/16/prepub 